\title{
O contrato social - entre a escala e o programa
}

\section{MILTON MEIRA DO NASCIMENTO}

"Antes de observar é preciso criar regras para as observações; é preciso uma escala para as medidas que tomamos. Nossos princípios de direito político são essa escala. Nossas medidas são as leis políticas de cada país."1

Com essas considerações que antecedem o resumo das idéias centrais do "Contrato Social", no livro V do "Emílio", Rousseau apresenta com muita precisão o que tinha em mente ao elaborar esta obra "de que me ocupava com mais gosto, na qual desejaria trabalhar durante toda a minha vida e que deveria, segundo acreditava, selar minha reputação". ${ }^{2}$ Trata-se, sem dúvida, da árdua tarefa de estabelecer os princípios do direito político. "O único moderno em condições de criar essa grande e inútil ciência fora o ilustre Montesquieu. Mas ele teve o cuidado de não tratar dos princípios do direito político; contentou-se com tratar dos princípios do direito positivo dos governos estabelecidos; e nada no mundo é mais diferente do que esses dois estudos. Entretanto, quem quer julgar sensatamente os governos como existem, é obrigado a reunir ambos: é preciso saber o que deve ser para bem julgar o que é. A maior dificuldade para esclarecer essas importantes matérias está em interessar um particular em discuti-las, em responder a estas duas perguntas: que importa e que posso fazer?"3

(1) Rousseau, J.-J., "Êmile", in Oeuvres Complètes, Paris, Pléiade, t. IV, p. 837.

(2) Rousseau, J.-J., "Les Confessions", in op. cit., t. I, p. 404.

(3) Rousseau, J.-J., "Êmile", in op. cit., p. 836 (grifos meus). 
Basta abrirmos o "Contrato Social" para nos certificarmos de que responder à questão "que posso fazer" está na dependência da resposta à primeira pergunta. Toda a obra, portanto, irá se desenvolver no plano do dever ser, no plano do direito, pois, resolver a questão do que importa é estabelecer os princípios do direito que tornarão possível o julgamento dos fatos. Desta forma, todo o "Contrato Social" não passará de uma grande "escala", na qual estarão todos os elementos constitutivos das relações de poder, desde o grau máximo da servidão até o grau máximo da liberdade política ou civil. $\hat{E}$ através da compreensão do "Contrato Social" como escala que se pode elucidar uma dificuldade importante da política, ou seja, "se as matérias de governo podem ser equitativamente tratadas". ${ }^{4}$

Não será, de forma alguma, na análise do direito positivo dos governos estabelecidos, onde o importante é a descrição e análise daquilo que é e não do que deve ser, que iremos encontrar uma forma de "tratar equitativamente" as matérias relacionadas com o governo. Resta tão-somente a abstração de toda e qualquer forma empírica de organização política, para nos ocuparmos daquilo que constitui a essência do direito político. Pois freqüentemente se confude o que "deve ser" com um plano de ação, ou algo como um projeto que um arquiteto elabora e que implica a sua realização, a sua execução prática. É preciso.não nos esquecermos da questão levantada por Rousseau quando está em jogo a atividade política concreta. "Se fosse príncipe ou legislador, não perderia meu tempo, dizendo o que deve ser feito; haveria de fazê-lo, ou calar-me". ${ }^{5} \mathrm{O}$ que nos indicam as leituras das "Considerações sobre o Governo da Polônia" e do "Projeto de Constituição para a Córsega" é que, quando se impõe uma ação ao nível da prática política concreta, a pergunta mais adequada não é sobre o que devemos fazer, mas sobre o que podemos fazer.

Em nenhum momento Rousseau tenta realizar o modelo político do "Contrato Social" como programa de ação, mas sua tarefa se limita a uma aplicação prática dos princípios estabelecidos no "Contrato", apenas como referência a um sistema de medidas. E não notamos também nenhum esforço do legislador para fazer realizar, na prática, um modelo arquitetado abstratamente, um modelo perfeito de organização política, que deveria ser imitado na prática. Vemos tanto no caso da Córsega, quanto no da Polônia, uma situação até mesmo inversa, isto é, o legislador agindo conforme as circunstâncias, organizando a vida

(4) Id., p. 837.

(5) Rousseau, J.-J., "Du Contrat Social”, in op. cit., t. III. p. 351 (grifos meus). 
política a partir das características próprias de cada um desses povos. E Rousseau, nesses casos, segue à risca um dos preceitos do "Contrato Social", quando fala das três espécies de leis que devem guiar a ação do legislador e se refere à "mais importante de todas, que não se grava nem no mármore, nem no bronze, mas no coração dos cidadãos; que faz a verdadeira constituição do Estado; que todos os dias ganha novas forças; que, quando as outras leis envelhecem ou se extinguem, as reanima ou as supre, conserva um povo no espírito de sua instituição e insensivelmente substitui a força da autoridade pela do hábito. Refirome aos usos e aos costumes, e, sobretudo, à opinião, essa parte desconhecida por nossos políticos, mas da qual depende o sucesso de todas as outras; parte de que se ocupa o grande legislador, enquanto parece limitar-se a regulamentos particulares que são apenas o arco da abóbada, da qual os costumes, mais lentos para nascerem, formam por fim a chave da indestrutível". ${ }^{6}$

Guiar-se pelos usos, costumes e opiniões não é exatamente fazer aquilo que aparece ao nível da ação possível? $\mathrm{O}$ que implica que não se pode, na prática, tratar equitativamente as matérias de governo, mas se deve levar em conta cada caso particular e dar a cada um deles a solução que for possível dentro das circunstâncias. Está claro, portanto, que a ação política não se guia por um modelo ou por um projeto abstrato, idealizado como a melhor forma de governo possível.

Em anexo a uma carta enviada ao Sr. Buttafuoco, Rousseau enumera tudo o que precisa saber antes de elaborar o projeto para a Córsega. "Um bom mapa da Córsega, no qual os vários distritos estejam registrados e diferenciados pelos seus nomes e, se possível, por cores. Uma descrição precisa da ilha; sua história natural, suas produções, sua cultura, sua divisão em distritos; o nome, o tamanho, a localização das cidades, dos burgos, das paróquias; o censo da população, tão exato quanto possível; o estado das fortalezas, dos portos; a indústria, as artes e a marinha; o comércio que se faz, o que se poderia fazer, etc. Qual a importância numérica e o prestígio do clero? Quais suas máximas? Qual a sua conduta em relação à pátria? Existem casas antigas, corpos privilegiados, nobreza. As cidades possuem direitos municipais? São muito ciosas deles? Quais os costumes do povo, seus gostos, suas ocupações, diversões, a ordem e as divisões militares, a disciplina, a maneira de guerrear, etc.? A história da nação até este momento, as leis, os estatutos; tudo o que se relaciona com a atual administração, os

(6) Id., p. 394 . 
inconvenientes que nela se apontam, o exercício da justiça, os rendimentos públicos, a orđem econômica, a maneira de estabelecer e arrecadar as taxas, o que, aproximadamente, o povo paga e o que pode pagar anualmente, e a relação entre uma e outra cifra." 7

O político, segundo Rousseau, não elabora antes o modelo ideal e depois tenta realizá-lo na prática. A eficácia de sua ação reside na capacidade com que consegue captar os usos, os costumes e as opiniões, isto é, as características essenciais de um povo, as condições específicas nas quais ele deve agir.

Se, portanto, no plano dos fatos, não se pode tratar igualmente as matérias de governo, o mesmo não se pode dizer quando se considera a esfera do direito, o plano do dever ser. Aparentemente vemos esboçar-se uma contradição entre o direito e o fato, entre a teoria e a prática. Mas, considerar esses dois níveis como contraditórios é não ver o seu funcionamento no pensamento político de Rousseau, é não se lembrar da advertência: "é preciso saber o que deve ser para bem julgar o que é". Luiz Roberto Salinas mostrou bem o funcionamento desses dois niveis, desfazendo os equívocos de uma leitura que insiste em apontar o cidadão de Genebra como um pensador contraditório:

"Tanto para fixar nossa conduta política diante de uma situação específica como para julgar a validade de um conjunto de instituições determinado não basta a referência exclusiva aos princípios gerais do direito, mas é necessário ainda perguntar por aquilo que convém a povos diferentes vivendo sob condições naturais distintas. A passagem de um nível para o outro - do direito em geral para o direito positivo — não é analítica: para julgar uma política determinada ou instituições vigentes, assim como para definir uma política ou elaborar um sistema de legislação positivo, é necessário levar em conta as diferenças entre os povos e não apenas a sua essência comum. Se à luz dos princípios gerais as instituições vigentes na Polônia parecem inaceitáveis, é possível que elas sejam válidas, se consideradas do ponto de vista das conveniências". 8

Estabelecer o plano do direito é criar o instrumental que tornará possível o julgamento dos fatos. Não se deve, pois, confundir um programa de ação com esse instrumento de medida, com essa escala. Esta

(7) Rousseau, J.-J., "Lettre à M. Buttafuoco, de 15/10/1764", in The Political Writtings of Jean-Jacques Rousseau, introdução e notas de C. E. Vaughan, Oxford, Basil Blackwell, 1962, v. II, p. 360.

(8) Fortes, Luiz Roberto Salinas, Rousseau: Da Teoria à Prática, São Paulo, Editora Âtica, 1976, p. 39. 
possui um caráter muito abrangente, isto é, nela podem-se enquadrar todas as formas de organização política possíveis com vários matizes. $\mathrm{O}$ programa, por sua vez, parte de um conhecimento prévio das condições concretas de uma determinada organização política e aparece mesmo como a solução prática numa determinada situação. Fazer da escala um programa é atribuir um papel secundário às condiçoes reais, concretas, a partir das quais se pode esboçar um projeto político. A escala, o instrumental, na sua totalidade, não pode estar em harmonia com a realidade factual empírica que está sendo objeto de análise. Mas, esta realidade deve corresponder a um determinado ponto da escala.

A não distinção entre os dois níveis em que Rousseau desenvolve o seu raciocínio é que tornará possível, já desde o "Discurso sobre a Origem da Desigualdade", um tipo de crítica como a de Voltaire. "Dá vontade de andar de quatro patas quando se lê vossa obra. Como, todavia, perdi esse hábito há mais de sessenta anos, sinto, infelizmente, que me é impossível retomá-lo, e deixo essa postura natural àqueles que dela são mais dignos do que vós, ou do que eu mesmo." 9 Nas anotações à margem do "Contrato Social", Voltaire deixará claro novamente que espera de Rousseau alguma coisa que vá modificar diretamente a vida política, um programa político, quando não considera a distinção fundamental que Rousseau faz entre soberania e governo. Quando, no capítulo II, do Livro II do "Contrato" Rousseau afirma que $o$ ato de declarar guerra e o de fazer a paz não são atos de soberania, Voltaire anota que são atos de soberania, "pois ato de soberania é ato de poder". ${ }^{10}$

A partir daí, surgirá uma linha interpretativa do "Contrato Social" sempre no sentido de tomá-lo como um programa para a ação política. Essa tradição é reforçada pelos revolucionários de 1789, reafirmada por Proudhon e muitos outros no século seguinte, e chega até os nossos dias.

Proudhon é veemente no seu ataque ao autor do "Contrato Social". "Rousseau, cuja autoridade nos guia há um século, nada compreendeu no que diz respeito ao contrato social. A ele cabe a culpa pelo desvio da Revolução de 1793, culpa essa que temos expiado com 57 anos de lutas estéreis, e que alguns homens menos reflexivos que ar-

(9) Voltaire, François-Marie Arouet, "Lettre de Voltaire a J.-J. Rousseau", de 30/8/1755, in Rousseau, Oeuvres Completes, Paris, Éditions du Seuil, t. II, 1971, p. 268.

(10) Voltaire, Le Sottisier, Suivi des Remarques sur le Discours sur l'Inégalité des Conditions et sur le Contrat Social. Paris, G. Frères, p. 317. 
dentes nos oferecem como uma tradição sagrada." $11 \mathrm{E}$ mais adiante acrescenta: "Onde, em vosso contrato, se acham meus direitos e meus deveres? Que prometi eu a meus concidadãos? Que me prometeram em troca? Dou a sentença: sem isto vosso sistema penal é uma extralimitação do poder; vosso estado jurídico uma usurpação flagrante; vossa organização política, vossos julgamentos, vossas ações, outros atos que implicam abuso. Vós, que negastes a propriedade, que condição, que herança me deixastes em vossa república para que ab-rogueis os meus direitos de julgar, encarcerar, tirar a honra e a existência? Acaso, declamador pérfido, gritastes tanto contra os expoliadores e os déspotas para logo entregar-me a eles sem defesa?". ${ }^{12}$

A considerar o "Contrato Social" nesses termos, não poderia ser outra a conclusão de Proudhon. Não teríamos senão vagas noções dos direitos e dos deveres de cada um. E não é difícil daí concluirmos que, em nome dos princípios esboçados no "Contrato Social", qualquer um poderia determinar, à sua maneira, quais deveriam ser os direitos e os deveres dos cidadãos. Até mesmo o mais aberto despotismo poderia se sustentar tomando como suporte os preceitos fundamentais do "Contrato". Basta que tais preceitos sejam tomados como parte de um programa político de ação.

Mais recentemente, seguindo esta mesma perspectiva de leitura, aliada a uma interpretação psicologista da obra de Rousseau, temos o trabalho de J. L. Talmon, para quem "Rousseau foi uma das mais desaptadas e egocêntricas naturezas que deixaram o testemunho de sua condição. Foi um punhado de contradições; um solitário, um anarquista, suspirando por voltar à natureza, dado aos sonhos, em oposição a todas as convenções sociais, sentimental e chorão, consciência abjeta, em contradição com tudo que o rodeava, por um lado, e, por outro, o admirador de Esparta e de Roma, o pregador da disciplina e da submissão do indivíduo à entidade coletiva. O segredo de sua dupla personalidade estava no fato de que o homem autoritário fora o sonho do paranóico atormentado. O 'Contrato Social' foi a sublimação do 'Discurso sobre a Origem da Desigualdade".". ${ }^{13}$

Talmon considera ao pé da letra a expressão "voltar ao estado de natureza", esquecendo-se da advertência feita por Rousseau na intro-

(11) Proudhon, P. J., La Idea de la Revolución en el Siglo XIX, tradução espanhola de Pedro Segui, México, Grijalbo, 1973, p. 117.

(12) Id., pp. 119-20.

(13) Talmon, J. L., The Origins of Totalitarian Democracy, Londres, Secker e Warbur, 1952, p. 38. 
dução do "Segundo Discurso". "Comecemos, pois, por afastar todos os fatos, pois eles não se prendem à questão. Não se devem considerar as pesquisas, em que se pode entrar neste assunto, como verdades históricas, mas somente como raciocínios hipotéticos e condicionais, mais apropriados a esclarecer a natureza das coisas do que a mostrar a verdadeira origem e semelhantes àquelas que, todos os dias, fazem nossos físicos sobre a formação do mundo. A religião nos ordena a crer que, tendo o próprio Deus tirado os homens do estado de natureza logo depois da criação, são eles desiguais porque assim o desejou; ela não nos proíbe, no entanto, de formar conjeturas extraídas unicamente da natureza do homem e dos seres que o circundam, acerca do que se teria transformado o gênero humano se fosse abandonado a si mesmo. Eis o que me perguntam e o que me proponho a examinar neste Discurso." 14

Por outro lado, afirmar que o "Contrato" é a sublimação do "Segundo Discurso" é nada mais do que dizer que Rousseau narra a gênese da desigualdade para logo depois legitimá-la. Ora, basta lembrarmos a fórmula do contrato proposto pelo rico no "Segundo Discurso" para notarmos o quão distante ela se acha daquela esboçada no "Contrato". Comparemos então as duas:

"Destituído de razões legítimas para justificar-se e de forças suficientes para defender-se, esmagando com facilidade um particular, mas sendo ele próprio esmagado por um grupo de bandidos, sozinho contra todos e não podendo, dados os ciúmes mútuos, unir-se com seus iguais contra os inimigos unidos pela esperança comum da pilhagem, o rico, forçado pela necessidade, acabou concebendo o projeto que foi o mais bem pensado que até então passou pelo espírito humano. Tal projeto consistiu em empregar em seu favor as próprias forças daqueles que o atacavam, fazer de seus adversários seus defensores, inspirar-lhes outras máximas e dar-lhes outras instituições que lhe fossem tão favoráveis quanto lhe era contrário o direito natural". ${ }^{15}$

O que notamos aí é uma canalização de forças em benefício do rico. Transformar os adversários em defensores só pode se constituir num grande e astucioso jogo político em que as forças atuantes têm a impressão de estarem trabalhando em benefício próprio, quando na realidade estão sendo enganadas e funcionando como a contracena para o exercício do poder daqueles que o detêm. No "Contrato Social", Rousseau volta a falar de um jogo de forças, mas empregadas com

(14) Rousseau, J.-J., "Discours sur l'Origine et les Fondements de l'Inégalité parmi les Hommes", in op. cit., p. 132.

(15) Id., p. 177. 
outro objetivo. "Ora, como os homens não podem engendrar novas forças, mas somente unir e orientar as já existentes, não têm eles outro meio de conservar-se senão formando, por agregação, um conjunto de forças, que possa sobrepujar a resistência, impelindo-as para um só móvel, levando-as a operar em concerto." 16

A questão que se coloca agora é como realizar esta tarefa. O texto do "Contrato", citado acima, não parece muito longe daquele do "Segundo Discurso". Mas, de agora em diante, a distinção vai-se tornando mais nítida. Vejamos como se esboça a proposta do rico:

"Com esse desígnio, depois de expor a seus vizinhos o horror de uma situação que os armava, a todos, uns contra os outros, que thes tornava as posses tão onerosas quanto o eram suas necessidades, e na qual ninguém encontrava a segurança, fosse na pobreza ou na riqueza, inventou facilmente razões especiosas para fazer com que aceitassem seu objetivo: 'Unamo-nos', disse-lhes, 'para defender os fracos da opressão, conter os ambiciosos e assegurar a cada um a posse daquilo que lhe pertence; instituamos regulamentos de justiça e de paz, aos quais todos sejam obrigados a conformar-se, que não abram exceção para ninguém e que, submetendo igualmente a deveres mútuos o poderoso e o fraco, reparem de certo modo os caprichos da fortuna. Em uma palavra, em lugar de voltar nossas forças contra nós mesmos, reunamo-nos num poder supremo que nos governe segundo sábias leis, que protejam e defendam todos os membros da associação, expulsem os inimigos comuns e nos mantenham em concórdia eterna'" ${ }^{17}$

Ao propor a criação de um poder supremo, o rico se coloca em posição de igualdade com os demais membros dessa associação, de uma igualdade jurídica, pois as leis garantem a cada um a posse de tudo o que lhe pertence. Ninguém pode, a partir de então, invadir o domínio alheio, sob pena de punição. Isto significa que, a partir do pacto, a desigualdade de riquezas fica assegurada. Se, no estado de natureza, a situação de instabilidade não tornava possível a posse permanente de alguma coisa sem riscos, agora, tudo aquilo que se adquiriu, por todos os meios possíveis, se torna propriedade indiscutível. Doravante há uma instância superior que garante a posse de tudo aquilo que já se tinha antes. O maior beneficiário dessa nova situação é aquele que possuía mais bens, o rico. Por outro lado, o pobre, que já não possuía muita coisa, continuará na mesma situação. As leis for-

(16) Rousseau, J.-J., “Du Contrat Social”, in op. cit., t. III, p. 360.

(17) Rousseau, J.-J., "Discours sur l'Origine et les Fondements de l'Inégalité parmi les Hommes, in op. cit., p. 177. 
necerão a todos a condição nova da igualdade jurídica apenas, e se constituirão no mascaramento da desigualdade de fato.

E o que encontramos no "Contrato" é algo bem diferente. "Estas cláusulas (do contrato), quando bem compreendidas, reduzem-se todas a uma só: a alienação total de cada associado, com todos os seus direitos, à comunidade toda, porque, em primeiro lugar, cada um dandose completamente, a condição é igual para todos, e, sendo a condição igual para todos, ninguém se interessa por torná-la onerosa para os demais." 18

Com a alienação de todos os seus direitos à comunidade, cada associado, em princípio, se coloca na condição de poder ceder parte ou todos os seus bens à comunidade, desde que houver uma necessidade de que isto se efetue. Os seus direitos individuais estarão subordinados aos de toda a comunidade, a qual se constituirá no poder soberano, único juiz da porção que deve caber a cada cidadão. "Ademais, fazendo-se a alienação sem reservas, a união é tão perfeita quanto possa ser e a nenhum associado restará algo mais a reclamar, pois, se restassem alguns direitos aos particulares, como não haveria nesse caso um superior que pudesse decidir entre eles e o público, cada qual, sendo de certo modo seu próprio juiz, logo pretenderia sê-lo de todos; o estado de natureza subsistiria, e a associação se tornaria necessariamente tirânica e vã." 19

Enquanto o rico propunha um contrato que the fosse mais vantajoso, tornando assegurado o seu poder sobre os mais fracos, nesta última fórmula o que Rousseau deixa claro é que o verdadeiro contrato não consagra a dominação de nenhum dos membros da associação.

Talvez se pudesse confundir a passagem do "Segundo Discurso" onde Rousseau afirma que, diante da proposta do rico, "todos correram ao encontro de seus grilhões", com a primeira frase com que se inicia o capítulo I, do livro I do "Contrato": "O homem nasce livre, e por toda a parte encontra-se a ferros". A condição descrita por Rousseau é a mesma nos dois textos, mas a seqüência do "Contrato" já aponta para um outro problema, o da legitimidade. "Como adveio tal mudança? Ignoro-o. Que poderá legitimá-la? Creio poder resolver esta questão." Não se trata aqui de legitimar a servidão, mas de analisar como a sociedade a tem tornado legítima e como se pode lançar as bases de um verdadeiro contrato anterior a toda convenção que tenha por fim organizar as várias formas de governo. "Antes, pois, de exa-

(18) Rousseau, J.-J., "Du Contrat Social", in op. cit., p. 361.

(19) Id. ibid. 
minar o ato pelo qual um povo elege um rei, conviria examinar o ato pelo qual um povo é povo, pois esse ato, sendo necessariamente anterior ao outro, constitui o verdadeiro fundamento da sociedade." 20

Como muito bem mostrou Goldschmidt, o contrato proposto pelo rico também é válido, pois, mesmo sendo enganados e com poucas condições para preverem as suas conseqüências, os homens, desde os mais grosseiros, até os mais previdentes, aceitaram o acordo proposto. ${ }^{21}$ Este pacto, que se situa ao nível da história hipotética da humanidade, não é suficiente para assegurar a liberdade a ninguém. Por isso mesmo, Rousseau acrescentaria logo a seguir: "Todos correram ao encontro de seus grilhões crendo assegurar sua liberdade". ${ }^{22}$

O contrato do "Segundo Discurso" situa-se, portanto, na grande escala de Rousseau, como um pacto possível, aliás, o mais provável, levando-se em conta a própria história das sociedades nascentes. $\hat{\mathrm{E}}$ mais um dos fatos políticos, embora hipotético, cuja leitura só é possível por referência à grande escala do "Contrato Social". A farsa que acompanha o pacto proposto pelo rico só pode ser considerada enquanto tal se for comparada, na escala, ao máximo de liberdade e de legitimidade que se inscrevem no pacto da alienação total. Longe, pois, de assegurar a liberdade, o acordo do "Discurso sobre a Desigualdade" consagra a servidão, embora conserve um certo grau de validade.

A proposta do rico insere-se numa certa lógica da desigualdade crescente e, enquanto programa para solucionar os conflitos do estado de natureza, é o que melhor convinha àquele que tinha muito a perder numa situação de instabilidade e sem um poder comum. Mas a farsa da história não se repete ao nível do direito, onde o único contrato capaz de instaurar a liberdade civil é aquele no qual "a condição é igual para todos" e, sendo assim, "ninguém se interessa em torná-la onerosa para os demais". Afirmação que pode ser entendida como um imperativo para a ação política e, num certo sentido, é. Mas não se deve esquecer as condições históricas nas quais deve realizar-se. $\hat{\mathrm{E}}$, pois, na combinação da exigência do máximo de liberdade, imposto pela escala, com a liberdade possível, ao nível da história, que se tornará possível a elaboração de um programa político.

Ao tomarem os princípios abstratos do "Contrato Social" como um programa político, os revolucionários de 89 inauguraram uma lei-

(20) Id., p. 359.

(21) Goldschmidt, Victor, Anthropologie et Politique - Les Principes du Système de Rousseau, Paris, Vrin, 1974, pp. 569-75.

(22) Rousseau, J.-J., "Discours sur l'Inégalité", in op. cit., p. 177. 
tura de Rousseau que seria amplamente difundida e aceita por muitos autores do século XIX e por alguns contemporâneos nossos, esquecendo-se de que, em Rousseau, a elaboração de um programa de ação exige muito mais do que o recurso a meras abstrações. Tomaram o instrumento de medida e esqueceram-se do que deveriam medir. Confundiram a escala com o programa. Ou melhor, esqueceram-se dele, porque o consideravam já feito por Rousseau. 